\title{
Determinants of Teachers' Job Satisfaction: School Culture Perspective
}

\author{
Bahir Adem Abdulahi \\ Department for Educational Planning and Management, Haramaya University, Ethiopia \\ Email: baharadem@yahoo.com
}

\begin{abstract}
The main purpose of this paper was to describe the effect of school culture factors on teachers' job satisfaction. Descriptive correlation design with mixed data approach was employed in four public secondary schools of Harari regional state, Ethiopia. The specific objectives were to describe the status of school culture and teachers job satisfaction, to identify the relationship between teachers' job satisfaction and school culture, to investigate the effect of school culture on teachers' job satisfaction and to sort out the determinants. The data information was gathered from teachers and educational leaders using questionnaire and interview guides respectively. Teachers' level of job satisfaction was low. There was no relationship between teachers' educational qualifications and their levels of job satisfaction. The relationship of teachers' job satisfaction in terms age, sex, salary, working experience, and marital status was not significant. There was association between teachers' job satisfaction and school culture, specifically with teachers' professional development and collaborative leadership practices. School culture and teachers' levels of qualification were predictors of job satisfaction in the schools. In order to enhance job satisfaction of teachers, the school leaders should strengthen and improve the existing continuous professional development program and collaborative leadership practices in the schools. Supervisors should support and facilitate professional development opportunities for teachers. Moreover, they should promote collaborative leadership practices in the schools. Future studies need to be considered in order to generalize the findings in different settings. Also undertake studies on the effect of job satisfaction and school culture on the quality of teaching-learning.
\end{abstract}

Keywords: determinants of job satisfaction; school culture; teachers'job satisfaction

\section{INTRODUCTION}

Out of the various inputs, human resources are a critical and most valuable asset in any organization as people are a vital component in the production of services or goods (Storey, 1995). From an education perspective, teachers play a major role in making the teaching-learning process effective and successful. Recognizing the importance of teachers, nowadays, schools are paying more emphasis to the issue of improving teachers' job satisfaction and school culture too. That is, not only to retain teachers on their jobs, but also to the successful achievement of educational targets.

Job satisfaction is the feeling and emotion that those employees are showing towards their jobs.
Employees' performances are affected by their levels of satisfaction, situational, and environmental factors, such as organizational climate (George, 2000; Gower, 2003). Employees' productivity is, to a large extent, influenced by job satisfaction. As a result, it is believed to be one of key factors in performance and productivity (Newsstrom, 2007; Hanan, 2009 cited in Naz and Sharma, 2017). This implies that teachers' job satisfaction and school environment are related and school culture is the most important factor in the realization of school objectives successfully.

Some studies indicated that employees' levels of satisfaction influence the individual's and organisation's 
level of performance (Srivastava, 2004; Zeinabadi, 2010; Rashid and Rashid, 2011; Lin, 2012 in Azumah, Ayisha and Mohammed, Safura and Tetteh, Rebecca, 2017). Other studies findings indicated that job satisfaction affects absenteeism and turnover of employees which in turn affect productivity of the organization (Froeschle and Sinkford, 2009; Wong and Heng, 2009 in Ibid). Sahitol and Vaisanen (2020), in their review of research, concluded that teachers' job satisfaction is one of the fundamental factors which determines the success of any school. The satisfied teachers contribute to the success of the school objectives (Muga, Onyango, and Jackline, 2017). In support of this, a positive relationship between teachers' levels of job satisfaction and the students' academic performances was found evident (Ekpenyong and Joseph 2017 in Sahitol and Vaisanen, 2020). Thus, the extent of teachers' job satisfaction challenges, not only the effort to retain teachers in the schools but also in improving their productivity.

It is well-noted that out of the resources in any organization, human resources should be used to the highest possible extent in order to achieve both, individual and organizational goals in an effective and efficient manner. However, this can be influenced by many factors. Individuals join organizations with some motives such as security of job and income, better prospects in future, satisfaction of psychological and social needs. These are complicated as every individual has different sets of needs at different spaces and times.

Job satisfaction is a key factor in productivity. The levels of teacher's satisfaction affect the levels of their attitudes towards their jobs which in turn may affect their performances and that of those they are interacting with. This is particularly true and observable in the teachinglearning process, as teachers have influence on their students' learning. Employees' satisfaction levels are reflected in their intrinsic and extrinsic willingness to put in their efforts (Malley, 2000). The review on research showed that the extent of teachers' job satisfaction has significant effect on collegial relations within school and learning outcomes (Crossman and Harris, 2006; Chaplain, 1995 cited in Getahun, Tefera and Burichew, 2016). Thus, the quality of education is related to the extent to which job satisfaction that teachers possess. Satisfied teachers can do their work effectively and efficiently, but if they are dissatisfied, there will be a negative impact on students' learning.

Teachers are the pivot of the education system. They are important figures, they are expected to remain important. But, there are some factors generating decrease in job satisfaction among teachers like, classroom size, lack of time and the sense of diminishing. School cultural factors may lead to high or low levels of satisfaction and performance (Mertler, 1992).

A school culture strongly affects not only individuals, but also group decision and action in the organization. Moreover, school culture ensures a sense of order and reduces employees' uncertainty and dissatisfaction (Belias and Koustelios, 2014). Thus, if school culture is not properly handled, it affects safety, extent of social problems in schools and students' academic achievement at large. School culture should always be monitored to remain positive. If school culture is deteriorating, school leadership needs to change the culture of the school (Taahyadin and Daud,2018).

Studies focused on hygiene factors, mostly ignore cultural aspects regardless of the existing diverse cultural background in the schools. Schools are dynamic environments, complex and peculiar social organisms held together by their unique culture Understanding cultural dimension is essential. Sorting out the pining cultural factor that influences a teacher's performance is ignored. Thus, as the employees' performance is mainly influenced by the extent of their job satisfaction, it is important to recognize, identify the basic fact, and provide appropriate opportunities and environments to meet teachers' job satisfaction in the schools.

The study conducted by Ayele (2014, cited in Berhanu, 2018) revealed that lack of good relation among teachers and with principals which was a major cause for low job satisfaction in secondary schools of Hadiya Zone, Ethiopia. But in his study, he did not consider school culture which might contribute to the observed low level of job satisfaction in the schools.

A study done on school culture and teachers' job satisfaction has shown that organizational culture influences employee's job satisfaction (Morris and Bloom, 2002). That is organizational culture plays a key role in predicting the level of satisfaction felt by teachers. Another study on school culture, in Thailand, showed that school culture was a strong predictive factor among many factors influencing the extent of teachers' job satisfaction (Treputtharat and Tayiam, 2014, cited in Duan, Du, and Yu, 2018)). Similar study was conducted on middle school teachers in Tehran and the result was consistent with aforementioned findings (Hosseinkhanzadeh, Hosseinkhanzadeh, and Yeganeh, 2013 in Duan et al., 2018). The research tools used in that Tehran study were the Darabi Organizational Culture Questionnaire and the Smith, Kandle, and Heulin Job Descriptive Index. Moreover, the investigation of the impact of school culture on primary teachers in Serbian demonstrated that 
there was a strong correlation between the dimensions of school culture and job satisfaction among the teachers. However, to measure school culture, the School Culture Survey (Saphier and King, 1985 cited in Gligorović and Nikolić,2016) which was modified by Edwards, Green and Lyons in 1996 was used. The instrument comprises only three dimensions: teacher professionalism and goal setting, professional treatment by the administration and teacher. That is ignoring other possible determinant variables.

Aforementioned studies examined mainly the relationship of school culture and teachers' job satisfaction while using school culture surveys without considering specific school culture factors or considering some of the factors. In addition to this gap, the relevance of the findings may be limited to the particular context, and there may exist variation in school culture in other countries (Zhu, Devos, and Tondeur, 2014 in Duan et al., 2018). In the study of job satisfaction, cultural difference among areas or countries should be acknowledged (Kwong, Wang, \& Clifton, 2010 in Gligorović and Nikolić,2016). Thus this study, on one side, aimed to investigate the relationship with school culture and teachers' job satisfaction focusing on more specific school culture factors. On the other side, employees' job satisfaction and related issues have become important topics in every workplace globally, particularly in Ethiopian education system.

In order to improve teacher's job satisfaction and school environment in general, strategies and programs like school improvement program (SIP) and continuous teacher development program (CPD) are introduced in the public schools of Ethiopia. As Harari regional state is one of the regions in Ethiopia, these programs are implemented in the public schools of the region. However, a little is known about school culture and teacher job satisfaction and factors affecting it in the region. Moreover most studies were limited to the hygiene factors without emphasis to the issue of school cultural aspects. Thus in the region, the need to explore the status of teachers' job satisfaction from a cultural perspective is crucial. This study sought to investigate job satisfaction in urban public secondary schools of Harari region, Ethiopia. It is restricted to teachers as they occupy central positions in schools and exploring their job satisfaction is crucial. Conceptually it was restricted to Herzberg's (1971) two factors theory for job satisfaction while school culture was based on that of Gruenert and Valentine (2006) work which comprise six components of school culture.

Hypothesis and question to guide the study were:

1. What is the status of teachers' job satisfaction and school culture in secondary schools of the study area?
2. a. $\mathrm{H}_{\mathrm{o}}$ : There is no positive relationship between teachers' job satisfaction and school culture.

b. $\mathrm{H}_{1}$ : There is a positive relationship between teachers' job satisfaction and school culture.

3. a. $\mathrm{H}_{\mathrm{o}}$ : The school culture does not affect teachers' job satisfaction in the schools understudy.

b. $\mathrm{H}_{1}$ : The school culture affects teachers' job satisfaction in the schools understudy.

4. Which factors of school culture are determinant of teachers' job satisfaction in the sample schools?

The purpose of this study was to describe the effect of school culture factors on the teachers' job satisfaction. The specific objectives were to elucidate the existing teachers' job satisfaction status and school culture, to investigate their relationship and determine whether school culture influences job satisfaction positively, and to sort out those school culture factors determining teachers' job satisfaction in schools.

Understanding job satisfaction helps to improve the working life of teachers via providing insights to the administrators responsible for designing and implementing staff development strategies and interventions within the secondary schools context. This study is important to the school community as it may inform educational leaders on the satisfaction and school culture that may be leveraged to ensure successful improvement of teachers' job satisfaction. Because of these, the ultimate objectives of the schools-teaching learning will be improved. Thus, through disclosing the existing relationship of variables related to satisfaction and school culture, this study is believed to contribute to the knowledge and practice in improving teachers' job satisfaction and creating productive school culture.

\section{LITERATURE REVIEW \\ Teachers' Job Satisfaction}

Job satisfaction refers to an individual's general attitude or feeling regarding his/her work and work environment. It is the sense of contentment and happiness of individuals in their current position (Kumara and Bhaskara,2007). Job satisfaction is how far the employees are satisfied with their work (Furnham, Eracleo, and Chamorro-Premuzic, 2009 in Eliyana, Ma'arif, and Muzakki,2019). Thus job satisfaction in school context is how teachers are feeling and satisfied with teaching work in their respective schools.

Job satisfaction is a key factor in productivity. Employees' satisfaction levels are reflected in their intrinsic and extrinsic willingness to put their efforts 
in their performance (Malley, 2000). Job satisfaction of employees is highly important in building up their motivation and efficiency. Higher job satisfaction indicates better employee performance (Shah, 1990).

Herzberg's two factors theory postulates that Hygiene factors help to prevent job dissatisfaction among employees (Herzberg, 1971). Hygiene variables are contextual factors surrounding the work. They include physical working conditions, job security, supervision, compensation, institution policy and administration, interpersonal relations and benefits. The fulfillments of these factors in the workplace do not actually motivate employees. However, proper handling of them can minimize the feeling of dissatisfaction and as the result the motivators will promote the employee's job satisfaction and encourage production (Belias and Koustelios, 2014). The implication is that as the teachers' extrinsic needs or hygiene factors are properly addressed or improved, it is likely that teachers put more effort to improve their students' learning and schools' performance.

\section{School Culture and Teachers' Job Satisfaction}

Different scholars defined organization's culture as common symbols, myths, rituals, values, beliefs, and habits that constitute the norms of an organization and distinguish its external constituencies (Tierney, 1988; Schein, 2000; Bolman and Deal, 1997; Rafaeli and Worline, 2000; DuFour and Eaker, 1998 cited in Brinton,2007).

It is the pattern of basic assumptions and norms that have been created by the member of organization while coping with adaptation and integration of the problems related to external and internal issues of organization respectively. It is believed that as they have worked well enough to be considered valid and should be shared among members as the correct way to perceive, think, and feel in relation to those problems. These indicate that organization culture describes the way things are done in an organization in order to solve both internal management problems and those related to customers, suppliers and environment (Schein,2004 cited in Belias and Koustelios,2014).

In school context, authors described school culture as a culture that exists within individual school which is expected to be conducive for teaching-learning and to its stakeholders. It is a system of shared orientations (norms, core values, and tacit assumptions) held by school members. It holds the unit together and gives it a distinct identity as well as it is a guiding values and beliefs in the way a school operates (Hoy, Tarter and Kottkamp ,1991 in Brinton, 2007; Bolman and Deal, 1994, 2013; Fullan, 2016 in DeMarco, 2018). School culture influences how people think and act in schools. It manifests itself in customs, stories, rituals, and ways of interacting with each other (Stoll, 1999 cited in DeMarco, 2018). It is characterized by deeply rooted traditions, values, and beliefs. Some of these characteristics are common across schools as well as some of them are unique and embedded in a particular school's history and location (Kruse and Louis,2009). These denote that schools are peculiar compared to other organizations as well as each school may have different cultures.

The aforementioned review implies that putting emphasis on the issues related to the organizational factors like work environment as well as school culture in which teaching work is important. Organizational culture is inseparable from human resources available in the organization, as it is manifested by employees' common beliefs and values. These influence the climate of the work environment and relationships among fellow employees in the organization. This in turn affects employees' feelings about their job and commitment. This may result in satisfaction or dissatisfaction of employees with their job to be performed (Belias and Koustelios, 2014). This implies that, in addition to the hygiene factors in schools, school culture contributes to the extent of teachers' job satisfaction in the school. When teachers feel a sense of pride and a climate of success in the schools, they feel suitable belonging and confidence in their school. That is because of better emotional and value commitment to their job, which may result in improved job satisfaction.

\section{Leaders and Organizational Culture}

Leaders play- in modifying school culture. Every organization has a culture, a history and underlying set of unwritten expectations that shape everything about the school. This informs or influences the way people think, feel, and act (Minnesota Department of Education (MDE,2019). Culture in school can be a constructive or destructive force. A large number of researchers indicated that school leader behaviour is the most important factor of teachers' job satisfaction and school climate (Jossanova-Vargovic and Pavlovic, 2014). According to Day and Sammons (2016), organisation's culture is changeable by their leaders. That is through establishing values, norms, and practices to be shared by the school community. Through setting expectations, defining rules and policies that shape behaviour in the school, leadership is a key element in establishing productive school culture. That is school leaders can impact the culture and climate of the school which serves the school community 
(Moffitt, 2007, in Tłuściak-Deliowska; Dernowski, and Gruenert,2017). Brankovic, Rodić, and Kostovic, 2012) stated that effective school leaders are continually working on changing the school, analysing and examining what their schools need to become better places for all students and employees.

Culture is a dynamic process which is subjected to change because of continuous interaction among internal and external stakeholders of the organization as well as promoted by leaders (Belias and Koustelios,2014). Effort to be successful shaping organizational culture, investigating and understanding it is critical (Stolp, 1994; Peterson, 2002; Reeves, 2006 in MDE,2019). As organization leaders have an important role in facilitating and modifying, school leaders can initiative change their respective organization. Investigating the existing culture, they are expected to promote and reinforce constructive elements supporting school expectation. Also they have to discourage and reshape destructive aspects of the school culture.

\section{Studies on Job Satisfaction}

The finding on educational level and age variation in explaining job satisfaction is mixed. Some study findings revealed significant difference in satisfaction because of employee age and sex (Hartman and Yrle, 1996 in Naz and Sharma, 2017). Age differences among teachers have a moderating effect on relationships between job satisfaction (Yucel and Bektas, 2012). However, research found no significant differences in job satisfaction between sexes (cited in kumara and Bhaskara ,2007). In contrast to this August and Waltman's (2004) study indicated that sex factor associated with job satisfaction (Bentley, Coates, Dobson, Goedegebuure, and Meek, 2013). In a study conducted on university teachers by Ali (2017 in Sahitol and Vaisanen,2020) no significant difference between male and female teachers was found in their job satisfaction.

As to the working experience of teachers, a significant relationship between job satisfaction and experience was not found but difference is observed in education levels (kumara and Bhaskara, 2007). In relation to salary, the relationship with job satisfaction found insignificant (Ahmed, Mohammed, and Tetteh, 2017).

Mwamwenda (1995) described that about 50\% of rural teachers are dissatisfied with their working conditions. Context study showed that among the working conditions, material, staff resources, and the prevailing managerial styles at their institutions are associated with job satisfaction (Bentley et al., 2013).
The investigation on the relationship between organizational culture and job satisfaction revealed positive significant relationship among the two variables (Hosseinkhanzadeh et al., 2013 in Duan et al., 2018). In the study done on Iranian teachers, the extent of adequacy of subject and pedagogical knowledge is most important factors in determining teachers' job satisfaction (Afshar and Doosti, 2016 in Sahitol and Vaisanen (2020). Similarly, the study conducted on primary Mathematics teachers, in Sweden, demonstrated that teachers who were more experienced in professional development tended to have higher levels of job (Toropova, Myrberg, and Johansson,2020). The study carried out by Mbogo (2016) found educational qualification level as the prime factor of satisfaction with a job.

\section{METHODOLOGY}

For this investigation, descriptive correlation research design with mixed qualitative and quantitative data approach was employed. Out of seven public secondary schools, in the 2018/19 academic year, in Harari regional state four urban schools were selected based on their location. The target population of this study was 221 subjects of which 205 were teachers, 12 principals and vice principals, and 4 supervisors. The sample of the study was determined using sample size determination formula of Yamane (1973). The total sample size used for this study was 140 of which129 teachers, 8 principles/vice and 3 supervisors who were selected using systematic random and purposive (based on experience) sampling technique respectively. To ensure equal representation, samples were proportionally drawn from each of the sample schools.

A questionnaire consisted of items on culture and job satisfaction was used. A School Culture Survey which was developed by Gruenert and Valentine was employed to collect data and information about the sample school's culture. As Gruenert (1998 in DeMarco, 2018), there is no single measure or score that determines school culture, but rather six factors constitute and manifest the school culture as whole. The School Culture Survey helps in providing important insight on the shared beliefs, values, behavioural patterns, and on relationships in a school (Gruenert and Valentine, 2006). This survey consists of six school culture factors, each of which measures a specific aspect of culture in a particular school. To measure these factors, there were 35 items with five Likert-scales with agree/disagree options. The second part consisted of 45 items related to motivators and hygiene factors which were rated with five scales ranging from very low to very high. 
According to Sekaran (2003), reliability refers to whether an instrument is consistent and stable. In the pilot study on the questionnaire using thirty-non-sampled participants, for Cronbach alpha $(\alpha=0.05)$, the obtained reliability coefficient was 0.89 . This result is within the second category of decision making criteria of George and Mallery (2003) that suggested a Cronbach's alpha result $>0.9$ excellent, $>0.8$ good, $>0.7$ acceptable,$<0.6$ questionable and $<0.5$ poor. Thus the instrument was good and reliable to be used for the study.

Out of the 129 questionnaire copies distributed to respondents, 123 were filled out and returned with $95.3 \%$ rate of return. However, a couple of them were incomplete and considered invalid for the purpose of this research. Thus analysis was carried out on data obtained from returned 121 copies of questionnaire which were complete information and valid ones. In addition to this, eight pertinent educational leaders (school principal/vice and three supervisors) were interviewed to substantiate quantitative results.

For the purpose of describing the status of existing school culture and teachers' job satisfaction in the sample schools, descriptive statistics (mean and standard deviation) and inferential statistics (t-test and regression) were utilized. In investigating association of job satisfaction and school culture, Pearson correlation $(\alpha=0.05)$ was used. Variables with insignificant coefficients $(\alpha=0.05)$ were excluded from each of the models. Factor analysis-rotated Varimax with Kaiser Normalization (Egan value $>1, \alpha=0.05$ ) was run to reduce six school culture factors into some significant ones. Stepwise regression was computed to identify the effect of the variables related to school culture. The information obtained through interviews were analysed and interpreted by describing or narrating them. The results were used in complementary with that of quantitative analysis of this study.

\section{CONCEPTUAL FRAMEWORK}

Various factors influence teachers' job satisfaction. According to Herzberg's two factors theory, hygiene factors are important in determining the extent of employees' job satisfaction. The school culture also determines how teachers behave, feel, and think. If the school culture is positive, it encourages commitment, increases motivation, and stimulates individuals to improve performance and feel competent (Peterson and Deal, 2009 cited in Confeld, 2016). This indicates that in addition to hygiene factors, constructive school culture contributes to the teachers' job satisfaction. Thus,

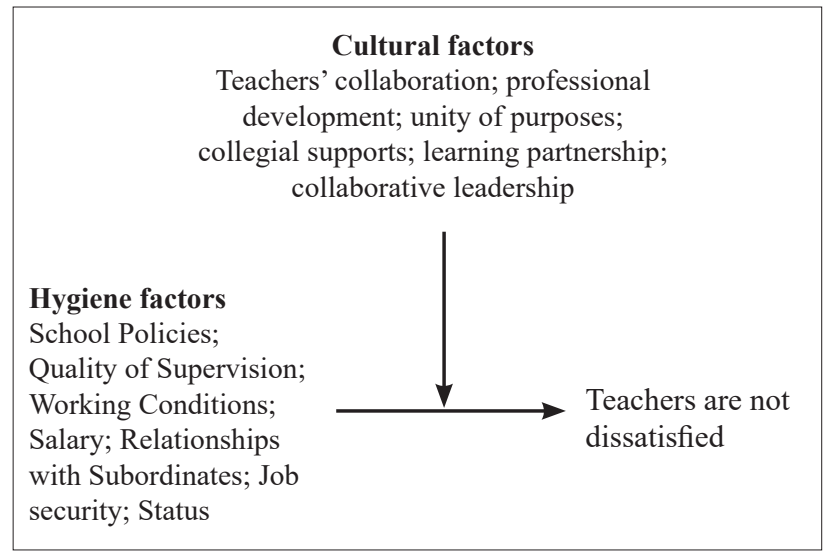

Figure 1. Conceptual framework for the study

teachers' feeling about school related factors affects their level of job satisfaction. As teachers have positive feelings or attitudes toward their school's hygiene and culture factors, to a lesser extent they are dissatisfied.

\section{RESULTS}

The main purpose of this study was to examine factors affecting teachers' job satisfaction. To this end, the results obtained were explicitly presented, analysed and interpreted in this section.

\section{Teachers' Job Satisfaction}

In an organization, the absence of hygiene factors such as interpersonal relation, working conditions, status, job security and salary generate job dissatisfaction while their occurrence creates job satisfaction. One of the objectives of this study was to identify the status of existing teachers' job satisfaction.

Based on the responses obtained the mean results for each of the factors are depicted as follows.

Table 1. Teachers' responses on their job satisfaction

\begin{tabular}{|l|c|c|}
\hline Hygiene Factors & Mean & Std. Dev \\
\hline Status & 2.16 & .83 \\
\hline Salary & 2.86 & .45 \\
\hline Security & 3.30 & .66 \\
\hline Policy & 3.12 & .73 \\
\hline Work condition & 2.95 & .37 \\
\hline Relation with supervisors & 2.83 & .61 \\
\hline Relationship with Subordinates & 3.32 & .49 \\
\hline Grand mean & $\mathbf{2 . 9 3}$ & \\
\hline
\end{tabular}


Herzberg, identified supervision, salary, working conditions are dissatisfies, the absence of which causes dissatisfaction. Their presence however, does not result in job satisfaction. As descriptive statistics result (see table 1 ), the mean for both school policy and administration in relation to the subordinates was slightly high (3.12 and 3.32). Similarly, there was a mean of 3.3 for job security. Similarly, the computed mean result for all dissatisfying factors was not indifferent (2.93). Supporting this, in the interview, one supervisor reported:

As to my observation, most fresh graduates are employed for teaching without having interest in teaching work. They take teaching positions to secure their employment status after then they look for other employment opportunities in another organization where they can get more salary and facilities. As they get other jobs they quit teaching. Some of them start studying for a degree program in other disciplines then to continue their study in education.

A school principal stated:

Some teachers are not that much ready to take comments and suggestions that help them to improve their teaching work. Their effort to improve their pedagogical and subject knowledge in the teaching- learning is very low.

The responses imply teachers join the teaching profession without having interest but to secure a job by taking readily available jobs. On the top of this turnover is common among teachers. Thus the teachers were dissatisfied in their job.

\section{Status of Existing School Culture}

Teachers' responses on the six school factors which indicate the status of the school culture are organized, analyzed and the results are shown in Table 2.

Table 2. Responses on school culture as perceived by teachers

\begin{tabular}{|l|c|c|}
\hline Components & Mean & Std. Dev \\
\hline Unity of Purpose & 3.23 & .49 \\
\hline Collegial support & 3.12 & .54 \\
\hline Learning partnership & 3.26 & .49 \\
\hline Teacher collaboration & 2.76 & .36 \\
\hline Collaborative leadership & 2.82 & .32 \\
\hline Professional development & 3.17 & .50 \\
\hline Grand mean & $\mathbf{3 . 0 5}$ & \\
\hline
\end{tabular}

Regarding collegial support, learning partnership, and Professional development the results were 3.17 ( $\mathrm{SD}=$ $.50), 3.12(\mathrm{SD}=.54)$, and $3.26(\mathrm{SD}=.49)$ respectively. These results were above average value (3) implying that these components of the school culture were slightly strong. Concerning that of the remaining components, means of less than three were observed for teacher collaboration (2.76, $\mathrm{SD}=.36$ ) and collaborative leadership (2.82, $\mathrm{SD}=.32)$. These signify the existence of weakness in these two aspects of school culture. In supporting this, in the interview conducted with supervisors and principals, one of the principals said:

In our school teachers are performing their teaching individually. In conducting action research, in improving lesson delivery or in handling student misbehavior in the classroom, they do not ask support or the help of other teachers in the school.

One of supervisors mentioned:

In the schools in which I am a supervisor, I have not seen teachers having activities they were doing in group or team. Teamwork is not common. In CPD (school based continuous professional development) most teachers are not ready to participate in sharing their experience and knowledge. Everyone thinks as if he is sufficient by himself. Some principals do not encourage teachers, except one teacher representative, to participate in the management of school. As one teacher finishes his daily work load or lesson, leaves the school. There is no chance to discuss among teachers about their work.

These disclosed that there is CPD in their schools but the practice in the schools is futile compared to what is expected. Teachers were doing their teaching work independently without supporting each other and collaboration. This implies the absence of working together or teamwork among teachers in the schools. This is consistent with the result of table 2 above which showed that the grand mean for school culture is slightly above average (3.05). Hence, this indicates that the status of school culture in the sample schools was fair.

\section{Factors affecting teachers' job satisfaction}

Teachers' job satisfaction may associate with many variables. One of the null hypotheses stated was that there is no positive relationship between teachers' job satisfaction and school culture. To test this hypothesis, 
correlation was conducted to identify variables having relation with job satisfaction. The results are presented below.

Table 3. Pearson correlation test result

\begin{tabular}{|c|c|c|c|c|c|c|c|c|c|}
\hline \multicolumn{2}{|c|}{\begin{tabular}{|l} 
Listwise \\
$\mathrm{N}=121$
\end{tabular}} & 3 & $\mathscr{\mathscr { R }}$ & 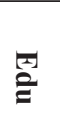 & $\underset{0}{\overrightarrow{d o g}}$ & $\tilde{\Omega}$ & tra & 幽 & 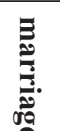 \\
\hline \multirow[b]{2}{*}{ js } & $\begin{array}{l}\text { Pearson } \\
\text { Corr. }\end{array}$ & 1 & .04 & $.80^{* *}$ & -.116 & $.15^{*}$ & .04 & .12 & -.01 \\
\hline & $\begin{array}{l}\text { Sig. } \\
\text { (1-tailed) }\end{array}$ & & .33 & .00 & .10 & .05 & .32 & .10 & .47 \\
\hline
\end{tabular}

The above result, in table 3 , describes that the relationship that exists between school culture and job satisfaction is positive and significant $(\mathrm{r}=.15, \rho=0.05)$. $(\mathrm{r}=.15, \rho=0.05)$. This is adequate evidence to reject the null hypothesis and accept the alternative hypothesis. Moreover, the variables sex, marriage, experience, and salary were removed from the model because of their insignificance $(\rho>0.05)$ (see table 3$)$ while educational background and school culture were retained $(\rho \leq 0.05)$. It is possible to say that sex, age ,experience and salary are not significantly important but educational background and school culture were affecting the extent of teachers' job satisfaction in the schools. The proportion to which these two factors contribute to teachers' job satisfaction was examined and the result is displayed in the next table.

Table 4. Results on predictor of job satisfaction

\begin{tabular}{|c|c|c|c|c|}
\hline Model & $\mathbf{R}$ & $\begin{array}{c}\text { R } \\
\text { Square }\end{array}$ & $\begin{array}{c}\text { Adjusted } \\
\text { R Square }\end{array}$ & $\begin{array}{c}\text { Std. Error of } \\
\text { the Estimate }\end{array}$ \\
\hline 1 & $.801^{\mathrm{a}}$ & .641 & .635 & .16977 \\
\hline \multicolumn{4}{|l}{} \\
a. Predictors: (Constant), SCUL(school culture), edu \\
(education)
\end{tabular}

The obtained result explained more than $64 \%$ of variation of the teachers' job satisfaction that was attributed to the teachers' education level and school culture variables. These two variables were important in improving the extent of teachers' job satisfaction in the sample schools.

The other hypothesis to be tested was the school culture does not affect teachers' job satisfaction. For this regression was computed to differentiate the contribution of each variable to teachers' job satisfaction. The result is displayed in the next table.
Table 5. Contributing variable to satisfaction

\begin{tabular}{|l|l|c|c|c|c|c|}
\hline \multicolumn{2}{|c|}{ Model } & \multicolumn{2}{|c|}{$\begin{array}{c}\text { Unstandardized } \\
\text { Coefficients }\end{array}$} & $\begin{array}{c}\text { Standardized } \\
\text { Coeff. }\end{array}$ & \multirow{2}{*}{ t } & \multirow{2}{*}{ Sig. } \\
\cline { 2 - 7 } & B & $\begin{array}{c}\text { Std. } \\
\text { Error }\end{array}$ & Beta & & \\
\hline \multirow{3}{*}{1} & (Constant) & .309 & .292 & & 1.058 & .292 \\
\cline { 2 - 7 } & Edu & .848 & .059 & .795 & 14.281 & .000 \\
\cline { 2 - 6 } & SCUL & .056 & .086 & .036 & .652 & .016 \\
\hline \multicolumn{7}{|l|}{ a. Dependent variable: teachers' job satisfaction } \\
\hline
\end{tabular}

The association that existed between school culture and job satisfaction was positive and significant (see table $5)$. The depicted result was sufficient condition to reject the null hypothesis $(\rho=0.016)$ and retain the alternative hypothesis. Thus, the implication was that teachers' level of education was highly $(\beta=0.848, \rho=.00)$ contributing to their level of job satisfaction in the schools. Moreover, the school culture, to some extent ( $\beta=.056)$, was significantly influencing teachers' job satisfaction as well.

\section{School cultural and job satisfaction}

The other objective of this study was to disclose school culture factors which determine teachers' job satisfaction. To identify the effect of school culture on job satisfaction, understanding the status of existing school culture in the schools is necessary. The following table exhibits, based on teachers' responses, the results of factor analysis.

Table 6. Rotated component matrix result

\begin{tabular}{|l|l|l|l|}
\hline \multirow{2}{*}{\multicolumn{1}{|c|}{ Components }} & \multicolumn{3}{c|}{ Factors } \\
\cline { 2 - 4 } & $\mathbf{1}$ & $\mathbf{2}$ & $\mathbf{3}$ \\
\hline Professional development (PD) & .711 & -.452 & -.042 \\
\hline Collaboration in leadership (CL) & .762 & .146 & -.100 \\
\hline Teachers' collaboration (TC) & -.031 & .832 & -.114 \\
\hline Unity of Purposes (UP) & -.190 & -.168 & .676 \\
\hline Learning partnership (LP) & -.446 & -.446 & -.295 \\
\hline Collegial supports (CS) & .094 & .099 & .745 \\
\hline $\begin{array}{l}\text { Extraction method: principal component analysis, Rotation } \\
\text { method: Varimax with Kaiser Normalization, rotation } \\
\text { converged in 5 iterations. }\end{array}$ \\
\hline
\end{tabular}

These indicated (see table 6) six school culture factors were computed to identify those factors explaining the teachers' job satisfaction. Three factors were extracted using factor analysis and the results disclosed that $\mathrm{PD}$ and $\mathrm{CL}$; TC; UP and CS were important factors in explaining the school culture. 
Table 7. Model summary of results in predicting job satisfaction using school culture variables

\begin{tabular}{|c|c|c|c|c|}
\hline Model & R & R Square & $\begin{array}{c}\text { Adjusted R } \\
\text { Square }\end{array}$ & $\begin{array}{c}\text { Std. Error of } \\
\text { the Estimate }\end{array}$ \\
\hline 1 & $.611^{\mathrm{a}}$ & .373 & .368 & .14034 \\
\hline 2 & $.807^{\mathrm{b}}$ & .652 & .646 & .10501 \\
\hline 3 & $.892^{\mathrm{c}}$ & .795 & .790 & .08088 \\
\hline
\end{tabular}

a. Predictors: (Constant), c1; Predictors: (Constant), c1, c3; Predictors: (Constant), c1, c2, c3

The summary result when school couture factors considered was shown in the table 7 above. The last model which consisted of the three components that is PD and CL(coponent1(c1)), TC(component 2(c2)), and UP and CS(component 3(c3)) explain about $80 \%$ of variation of school culture. However, because of collinearity of the factors with job satisfaction, only teachers' professional development and collaborative leadership factors in the schools were retained. Hence, these two factors explained most of the variation and were responsible for more than $37 \%$ influence on the teachers' job satisfaction.

Table 8. Results for coefficients

\begin{tabular}{|l|l|c|c|c|c|c|}
\hline \multirow{2}{*}{ Model } & \multicolumn{2}{|c|}{$\begin{array}{c}\text { Unstandardized } \\
\text { coefficients }\end{array}$} & $\begin{array}{c}\text { Standardized } \\
\text { coeff. }\end{array}$ & \multirow{2}{*}{ t } & \multirow{2}{*}{ Sig. } \\
\cline { 2 - 7 } & B & $\begin{array}{c}\text { Std. } \\
\text { Error }\end{array}$ & Beta & & \\
\hline \multirow{2}{*}{1} & (Constant) & 2.022 & .117 & & 17.243 & .000 \\
\cline { 2 - 7 } & $\mathrm{c} 1$ & .327 & .039 & .611 & 8.416 & .000 \\
\hline
\end{tabular}

The prediction model implies that both teachers' professional development and collaborative leadership in the schools are positively and significantly $(\rho=.00)$ contributing to the job satisfaction of teachers. From this result and earlier analysis that disclosed 37\% of explanation in the model, one can infer that the status of teacher professional development as well as collaborative leadership practice in the schools are important to improve the teachers' job satisfaction.

\section{DISCUSSION}

Out of the various inputs that go to school, teachers have paramount importance. Teachers' feeling towards their work is influenced by different factors. Understanding the level of work satisfaction is critical and should not be ignored.This study aimed to investigate the effect of school culture on the job satisfaction of secondary school of Harari region, Ethiopia. It revealed that teachers' job satisfaction was low.

Review of literature indicates that there are variables which affect teachers' job satisfaction. Inline to this, the finding of this study disclosed that there was no significant job satisfaction variation because of sex and age difference among teachers. This refutes the findings of Hartman and Yrle (1996 in Naz and Sharma, 2017) which disclosed that age of employee and sex lead to significant difference in their level of job satisfaction. Nevertheless, the finding is consistent with that of Mishra and Dkhar (2016 cited in Sahitol and Vaisanen, 2020) who found no significant differences in job satisfaction between sexes of teachers. This might be because this study considered many variables which are very important to explain teachers' job satisfaction regardless of sex and age of the teachers'.

According to finding of the current there is no relationship between work experience and teachers' job satisfaction level. This finding consistent with study result of kumara and Bhaskara (2007) which confirmed that there was no significant relationship between job satisfaction and experience. The absence of relationship between teachers' job satisfaction and work experience in this study indicates that how long work experience teachers have is not related to their level of job satisfaction.

The finding of this study revealed that the teachers' education level is contributing to the level of their job satisfaction. This goes with the finding of Mbogo (2016) who reported that educational level influences the level of job satisfaction and causes differences. Teachers' education level positively associated with the school culture as well as significantly affects and explains teacher's job satisfaction. This might be for the fact that those with higher level education have better mastery of subjects and professional skill that may result in better confidence in their work. Moreover, they may enjoy better salaries compared to other teachers who have low levels of educational qualification. This implies that improving teachers' knowledge and professional skills, which they require to carry out their responsibility, may reduce their dissatisfaction toward their job in the school

The current study revealed that the relationship between school culture and job satisfaction was positive and significant. This is consistent with the previous findings (Treputtharat and Tayiam,2014; Hosseinkhanzadeh et al., 2013 cited in Duan et al., 2018; Gligorović and Nikolić,2016) which demonstrated the existence of significant positive relationship between school culture and teachers' job satisfaction. It also agrees with that of Mertler(1992) which stated that school culture 
factors affect the level of employees' job satisfaction in organization. Thus assumptions, norms, values, and beliefs which are commonly held by teachers in school affect teachers' level of job satisfaction. This implies that when culture components are improved in the schools, the existing teachers' job satisfaction will be enhanced.

Teachers' job satisfaction is affected by different factors, but some of the factors are very important over the others. This investigation indicated that, out of the six components of school culture, professional development and collaborative leadership were prime factors and predictors of teachers' job satisfaction.

Related to the finding of professional development, it is supported by the find of Afshar and Doosti (2016 cited in Sahitol and Vaisanen, 2020) who concluded, in Iranian, that subject and pedagogical knowledge of teachers are important factors in determining teachers' satisfaction. It is also in harmony with the finding of study on teachers, in Sweden, which proved that teachers with more experience of professional development tended to have higher levels of job satisfaction (Toropova et al.,2020). That is promoting professionalism in the schools; provides opportunity to have better knowledge and skill. In addition to this, the existence of strong collaborative leadership behaviour in the schools, lead to confidence and belonging to be developed among teachers. This in turn elevates the level of teachers' job satisfaction. Hence, aforementioned professional development and collaborative leadership are important and they are determinant of teachers' job satisfaction and should not be ignored. School leadership can enhance and shape school culture components. Unless more emphasis is placed on school principals' leadership role, the existing professional development and collaborative leadership practices will negatively affect school culture and teachers' job satisfaction. As a result, quality problems in the students' learning will perpetuate in the schools.

\section{CONCLUSION}

Job satisfaction is an interplay result of various feelings towards factors related to school and teachers. Absence or having poor professional development programs in schools denies teachers to have opportunities to abreast their knowledge and teaching profession. As a result they may lack competence, confidence and demonstrate disaffection to their teaching work. Unless dissatisfaction factors are mitigated or removed in the schools, the motivation and commitment of teachers will be affected. This problem will challenge the realization of school objectives in an effective and efficient manner.
Hence, leaders and teachers should pay more emphasis to promote high job satisfaction among teachers. The school leaders should work on knowledge management in the school, particularly strengthening the existing continuous professional development (CPD) among teachers in the schools. As school leaders are responsible for realizing strong academic culture in the schools, they should encourage teachers to participate and benefit from CPD. The existing school situations require more attention and value to be given, particularly to teachers' participation, encouraging and praising, sharing ideas and teamwork in the schools. Hence school leaders should excel the collaborative leadership practices in the schools. Moreover, supervisors ought to support and contribute to the enhancement and effectiveness of professional development programs and collaborative leadership behaviors in the schools. In the effort to strength CPD and collaborative leadership in the schools, teachers should be cooperative and active participants too.

The findings of this study is not generalizable on primary and all secondary schools as the study was delimited to only four urban secondary schools of Harari region. Considering different locations, school levels and sample size may show different results. It is recommended that additional investigations be conducted in other geographic areas, in order to compare and contrast the findings of the current study. Constructive school culture contributes to the quality of the school environment and to teachers' job satisfaction that would help to improve the quality of student learning. Thus interested one may study the effect of job satisfaction and school culture on the quality of teaching-learning as well.

\section{ACKNOWLEDGEMENT}

I would like to express my heart-felt thanks and appreciation to Augustine Sesay ( $\mathrm{PhD}$ ) for editing the manuscript. It is my pleasure also to extend my appreciation to school leaders and teachers of the sample schools who were cooperative and contributed to this study, through providing information and suggestions.

\section{REFERENCES}

Ahmed, A., Mohammed, S., \& Tetteh R. (2017). An empirical study of job satisfaction of university staff. Sunyani Technical University. Online at https://mpra.ub.unimuenchen.de/79674/

Anthony, L. DeMarco (2018). The relationship between distributive leadership, school culture, and teacher self-efficacy at the middle school level. Dissertation, Seton Hall University. 
Aziri, B. (2011). Job satisfaction: A literature review. Management research and practice, 3(4),77-86.

Azumah A., Ayisha \& Mohammed, Safura \& Tetteh, Rebecca (2017). An empirical study of Job satisfaction of university staff. Online at https://mpra.ub.unimuenchen.de/79674/.

Bahamonde-Gunnell, M. (2000). Teachers' perceptions of school culture in relation to job satisfaction and commitment. Dissertation, Western University.

Belias, D. \& Koustelios, A. (2014). Organizational culture and job satisfaction: A review. International Review of Management and Marketing, 4(2),132-149.

Bentley P. J., Coates, H., Ian R. Dobson, Leo Goedegebuure, \& V. Lynn Meek (2013). Job satisfaction around the world. Springer Dordrecht Heidelberg. New York London (pp.1-11).

Berhanu Shanko D. (2018). Teachers' Job Satisfaction And Professional Commitment In Government Secondary Schools In Hadiya Zone. Unpublished Doctoral Dissertation, AAU.

Brankovic, N., Rodić, V., \& Kostovic S. (2012). Determination of indicators of school culture in primary schools. The New Educational Review, 3, 45-55.

Brinton, C. M. (2007). Comparing perceptions about collaborative culture from certified and non-certified staff members through the adaptation of the school culture survey-teacher form. Dissertation, University of Missouri-columbia.

Confeld, Sara (2016). The Importance of a Positive School Culture. MA thesis, Faculty of Adler Graduate School.

Day, C. and Sammons, P. (2016). Successful School Leadership. Education development trust.

Ileana, A., Ma'arif, S., Muzakki (2019). Job satisfaction and organizational commitment effect in the transformational leadership towards employee performance. European Research on Management and Business Economics.

Duan, X., Du, X., \& Yu, K. (2018).School Culture and School Effectiveness: The Mediating Effect of Teachers' Job Satisfaction. International Journal of Learning, Teaching and Educational Research, 17(5), 15-25.

Getahun, T. Tefera, B. F. \& Burichew, A. H. (2016). Teacher's Job Satisfaction And Its Relationship With Organizational Commitment In Ethiopian Primary Schools: Focus On Primary Schools of Bonga Town. European Scientific Journal, 12(13), 380-401.

George, D. and Mallery, P. (2003). Calculating, interpreting and reporting Crobach's Alpha Reliability Coefficient for likert t-scale. Middle West Research to practice conference in Adult, continuing and community Education.
Gligorović, B. \& Nikolić, M. (2016).The Impact of School Culture on Serbian Primary Teachers' Job Satisfaction. H. U. Journal of Education, 31(2), 231248.

Gruenert, S. \& Valentine, J. (2006). Project assist: School culture survey. Retrieved from http://mllc.missouri. edu/3E_ast_school\%20culture.php

Herzberg, F. (1971). Work and the nature of man. New York: The World Publishing Company.

Herzberg, F. (1967). The motivation to work. London: John Wiley \& Sons, Inc

Josanov-Vrgovic, I., \& Pavlovic, N. (2014). Relationship between the school principal leadership style and teacher's job satisfaction in Serbia. Montenegrin Journal of Economics, 10(1), 43-57.

Kanter, R. M. (1983). The Change Masters. Simon \& Schuster, New York.

Kothari, C.R. (2004). Research Methodology. New Age International, New Delhi.

Kumara, J. \& Bhaskara, D. (2007). Job Satisfaction of Teachers. Discovery publishing house, New Delhi, India.

Mbogo, R. W. (2016). The Perceptions of distance education personnel of the relationship between work conditions and their job satisfaction in Kenya's Christian higher education. British Journal of Education, 4(4), 38-48.

Mertler, C.A. (1992). Teacher motivation and job satisfaction of public school teachers.

Minnesota Department of Education (MDE) (2019). Change leadership: A guide for school leaders. Minnesota.

Muga, O. P., Onyango, A. G., \& Jackline, N. (2017). Levels of teachers' job satisfaction in public secondary schools in Siaya, Kisumu and Kajiado Counties, Kenya. European Journal of Education Studies, 3(8), 684-702.

Mwamwenda, T.S. (1995). Job satisfaction among secondary school teachers in Transkei. South African Journal of Education, (15),84-86.

Naz S. \& Sharma H. (2017). Job satisfaction among different working organizations: A literature review. Research Journal of Social Science and Management, 7(6), 29-37.

Sahito, Z. \& Vaisanen, P. (2020). A literature review on teachers' job satisfaction in developing countries: Recommendations and solutions for the enhancement of the job. Review of Education: An international Journal of Major Studies in Education, 8(1), 3-34.

Samreen, H.S. (2017). Job satisfaction among different working organizations: A literature review. Research Journal of Social Science and Management, 7(6), 29-37.

Shah, A. K.(1990). Job satisfaction in cooperative organization: An empirical study. Co-operative training college, Kharguli Guwahati-4 Assam. 
Sharon, D. Kruse \& Louis K.S. (2009). Changing School Culture. Corwin Press.

Storey, J. (1995). Human Resource Management. A Critical Text ( $1^{\text {st }}$ ed.). London, New York: Routledge.

Taahyadin, F. \& Daud, Y. (2018). School culture and school improvement challenges in kedah. Journal of Business and Management, 20(6), 25-30.

Tłuściak-Deliowska, A.; Dernowska, U., \& Gruenert, S. (2017). How school achievements interplay with school culture and principal behaviors: A comparative study of two middle schools. International Journal of Psycho-Educational Sciences, 6(1), 11-22.
Toropova A., Myrberg, E., \& Johansson S. (2020). Teacher job satisfaction: the importance of school working conditions and teacher characteristics. Educational Review. DOI: 10.1080/00131911.2019.1705247. Retrieved in April 2020 from- https://doi.org/10.10 80/00131911.2019.1705247.

Yucel, I., \& Bektas, C. (2012). Job satisfaction, organizational commitment and demographic characteristics among teachers in Turkey: Younger is better? Sciverse science direct, Elsevier Ltd. 